\title{
The Mink
}

\author{
The Mink. N. Dunstone. T \& A D Poyser Ltd., London, 1993. 232 pp. ISBN 0-85661-080-1.
}

The mink arouses the interest of many people, including biologists, hunters, game-keepers, farmers, businessmen and even dignified ladies. Therefore, it is not surprising that mink is perceived variously, according to this who and how looks at this animal. "Venus and Satan have never been so curiously confused as in the popular image of the mink" - writes Dunstone in the introduction to his book. Thus, the more difficult seems an effort to portrey the mink objectively. Nigel Dunstone, who studied this predator for nearly twenty years and became an expert in its biology, took upon himself the challenge of writing a monograph.

The name "mink" refers to American mink Mustela vison and European mink Mustela lutreola. The book is practically devoted to the former species and could be entitled "The American Mink" as well. In the monograph, data on the European mink are scarce and based on very few sources. Mustela lutreola is not as well studied as M. vison and of course the author can not be blamed for the lack of information on this species. Most research on European mink were carried out in the former USSR and their results (a few of them could be cited in the book, e.g. Tumanov and Smelov 1980, Shubnikova 1982, Moshonkin 1983) were published in Russian, often in local journals. Probably, it would have been much better if the author had resigned to intersperce each chapter with disproportionately short notes about Mustela lutreola and the whole information about this species had placed in the separate chapter. The "shadow" of the European mink wanders in the whole book causing some obscureness, for example in Fig. 2.5, which is described as "Skull of mink" (in fact it is a skull of American mink), while it is known that skulls and teeth of both species differ (the reader gets this information in the text on the next page).

The book consists of 11 chapters, in which many aspects of the mink biology are presented and discussed. The reader obtains comprehensive knowledge about morphology, anatomy and phylogeny of the predator. The short chapter informs about minks tracks and signs. The geographical distribution of both minks is presented, in detail for British Isles and less precisely for the other countries. Unfortunately, distribution maps of the European (Fig. 4.6) and American mink (Fig. 4.5) are inaccurate; for example, the presence of $M$. vison in Poland is not marked (although its distribution in this country is mentioned in the text) and also the present range of M. lutreola in Belarus and Russia is omitted.

Interesting information can be found in the chapters devoted to the morphological and behavioural adaptations of the American mink to the semiaquatic habitat and its food and foraging. Much of presented data come from the authors own studies, which were carried out in laboratory and in the field. The mink adaptations to semiaquatic environments are a composition of those found in other mustelids, however comparing to its relatives, mink is less specialized species. It does not swim as well as otter and does not hunt rodents in their burrows as efficiently as weasel. The mink is very versatile predator and this reveals in its locomotive abilities, variety of inhabited environments and particulary in its generalistic food habits. The big ecological plasticity is undoubtedly the reason of the successful expansion of the American mink in Europe and Asia.

In the next chapters Dunstone discusses habitat requirements, activity patterns and some aspects of population biology including social interactions, spatial structure, sex ratios, breeding and mortality of mink. Notes concerning trapping the mink and the use of radio-tracking technique are valuable. The mink is presented as an important game and breeding animal. Detailed information 
about the exploitation of wild populations, mink farming, coat colours and even about fur production and marketing can be found in the book. A little bit too long lecture on the Mendelian genetics unnecessarily extends this chapter.

Particullary interesting, however, is the last chapter, "exploding the mink myth" and covering interactions of American mink with man and animals. Dunstone tries to break down opinions that the mink is a destroyer of all living creatures, causing disaster in the occupied habitats. The author asserts that due to the generalistic food habits, the minks impact on the prey populations is negligible. The only exception are colonial ground-nesting sea-birds. In Dunstone's opinion, suspicion of the mink to the total extermination of any bird or mammal species seems to be irrational. Also, the view that the competition with mink may lead to the decline in numbers of some native carnivores (especially otters), has been shaken. The author states that in Europe the American mink took up successfuly the vacant ecological niche after the extinction of its European relative. The attempts to control American mink populations are beside the purpose. In Dunstone's opinion, the false belief that the mink is a pest in aquatic habitats, may have dire consequences. It diverts our attention from the real factors affecting wildlife.

The book is richly illustrated with figures, tables and photographs (including 24 colour plates). However, many figures are incompletely explained (e.g. Fig. 6.15, 6.16, 8.3, 8.4, 10.2) and at least in one table (Tab. 6.1) the sum of percentage is incorrect. Some figures (Fig. 7.8, 7.9, 11.6) are totally contradictory to the text. For example Fig. 11.6 shows that the dietary overlap between the mink and otter is the biggest in summer whereas in the text the information is reversed. This mistake does not occur in the original source (Erlinge 1972). Fig. 6.11 is wrongly described as Fig. 6.10. Even legends for two colour photographs (Plate 1 and 20) are false. Few other mistakes as, for example, unproper latin name of the American marten Martes americana, can be found in the book.

The author bases on the very comprehensive literature which is the big advantage of this book. Most sources come from North America, British Isles and Sweden and this can be easily explained by the fact that most research on mink were undertaken in the mentioned above parts of the world. Data from other countries (especially from Eastern Europe and Russia) are less numerous and often published in journals that are not easy to attain. Unfortunately, some interesting articles from this part of Europe (Sidorovich 1991a, b, 1992, 1993, Pikulik and Sidorovich 1991) were presented too late to be cited in the book. However, information from few older sources (e.g. Popov 1949, Serzhanin 1961, Vaseneva 1963, Grigorev and Egorov 1969, Tumanov and Smelov 1980, Shubnikova 1982, Sidorovich 1988) could enrich the monograph of the mink. Reading some of the chapters one might have the impression that discussed issues concern only "the British" American mink. Minks inhabiting sea coasts and minks feeding on rabbits are much different from those living in other parts of our continent. Thus, many observations and conclusions from one area may not fit to the other regions. Generalizations are often inadvisable and lead to evident mistakes as, for example, the explanation that the mink does not compete with polecat and stoat. The author argues that these mustelids feed mainly on rabbits which populations are too numerous to be a limiting factor. Whereas in some studies in Eastern Europe it has been found that both minks and polecats may intensively hunt frogs (Tumanov and Smelov 1980, Brzeziński and Żurowski 1992, Sidorovich 1992, Jędrzejewski et al. 1993).

Every reader will find in this book interesting issues. There are, however, some questions which seem to be especially important. One of these is how the American minks affect populations of their prey during the initial period of their presence in a particular area and how does it change as the time passes away? Other important question is what the interactions between the American and European mink are and how to protect the native European species? These problems are more or less widely discussed in the book, but still more studies on both species are needed to answer such (and many other) questions.

Nigel Dunstone's book could be little bit more scrupulously prepared but it is undoubtedly a valuable monograph. People who are interested in minks (both scientists and amatours) should not overlook this volume. 


\section{References}

Brzeziński M. and Żurowski W. 1992. Spring diet of the American mink Mustela vison in the Mazurian and Brodnica Lakelands, northern Poland. Acta theriol. 37: 193-198.

Jędrzejewski W., Jędrzejewska B. and Brzeziński M. 1993. Winter habitat selection and feeding habits of polecats (Mustela putorius) in the Białowieża National Park, Poland. Z. Säugetierk. 58: $75-83$.

Erlinge S. 1972. Interspecific relations between otter (Lutra lutra) and mink (Mustela vison) in Sweden. Oikos 23: 327-335.

Grigorev N. D. and Egorov I. E. 1969. [On the biocenotic connections of the American mink with the river otter in the Bashkir Autonomous Soviet Socialistic Republic]. Sb. Tr. Vses. n.-issled. In-ta Životn. Syrja Pušniny 22: 26-32. [In Russian]

Moshonkin N. N. 1983. The reproductive cycle in females of the European mink (Lutreola lutreola). Zool. Ž . 62: 1879-1883. [In Russian with English summary]

Pikulik M. M. and Sidorovich V. E. 1991. [Evaluation of structural and functional relations of populations of semi-aquatic predators and amphibians in the Byelorussia]. Ekologiya (Sverdl.) 6: 28-36. [In Russian]

Popov V. A. 1949. [Materials on the ecology of the mink (Mustela vison Briss) and the results of its acclimatisation in the Tatar ASSR]. Tr. Kazan. Finiala AN SSSR, 2: 1-140. [In Russian]

Seržanin I. N. 1961. [Mammals of Byelorussia]. Nauka i Tehnika, Minsk: 1-315. [In Russian]

Shubnikova O. N. 1982. [Results of introduction of American mink (Mustela vison Briss) in RSFSR and problem of it's relationships with the native species (Mustela lutreola L.)]. In: Promyslovye zveri RSFSR: prostranstvennye i vremennye izmenenija naselenija. Moskva: 64-90. [In Russian]

Sidorovich V. E. 1988. [Typology of waterbodies as habitats of semi-aquatic carnivores, numbers and densities of their populations in Byelorussia]. Preprint VINITI No. 7935 - V88. Minsk: 1-54. [In Russian]

Sidorovich V. E. 1991a. [Diet and relations of otter (Lutra lutra L.) and American mink (Mustela vison Schreb.) in Byelorussia]. Preprint VINITI No. 1431-V91. Minsk: 1-99. [In Russian]

Sidorovich V. E. 1991b. Distribution and status of minks in Byelorussia. Mustelid and Viverrid Conserv. 5: 14.

Sidorovich V. E. 1992. Comparative analysis of the diets of European mink (Mustela lutreola), American mink (M. vison) and polecat (M. putorius). Small Carnivore Conserv. 6: 2-4.

Sidorovich V. E. 1993. Reproductive plasticity of the American mink Mustela vison in Belarus. Acta theriol. 38: 175-183.

Tumanov I. L. and Smelov V. A. 1980. The food connections of the Mustelidae in the North-west of the RSFSR. Zool. Ž. 59: 1536-1544 [In Russian with English summary]

Vaseneva A. I. 1963. [The economic advisability of the acclimatisation of mink in the Far East]. Sb. nauč.-tehn. Inf. VNIIZHP, 6(9). [In Russian]

Marcin BRZEZIŃSKI, Department of Ecology, University of Warsaw, Krakowskie Przedmieście 26/28, 00-927 Warsaw, Poland 